\title{
Salvador Alvarado y las elecciones de 1920, una candidatura olvidada
}

\author{
Salvador Alvarado and the 1920 \\ Elections: A Forgotten Nomination
}

\author{
Francisco Iván Méndez Lara* \\ Posgrado en Historia \\ Universidad Nacional Autónoma de México, México \\ (D) orcid.org/0000-0002-4981-3040 \\ ivan.mendez.lara@gmail.com
}

Resumen: El presente artículo muestra una de las facetas menos estudiadas del general Salvador Alvarado: su papel en la sucesión presidencial de 1920. A través de la revisión de fuentes poco exploradas como los periódicos $\mathrm{El} \mathrm{He-}$ raldo de México y El Monitor Republicano podrá observarse la complejidad y tensión del ambiente político en la coyuntura electoral. Alvarado modificó su postura conforme avanzó la contienda, de una actitud belicosa que lo llevó a crear su propio partido político contra los generales Pablo González y Álvaro Obregón, pasó a ser un aliado del grupo sonorense en la lucha contra la imposición del candidato carrancista, Ignacio Bonillas. Además de comprender a un Alvarado interesado en la silla presidencial, este trabajo muestra el accionar de los periódicos capitalinos como espacios de discusión e impulsores de plataformas políticas en las elecciones que posicionaron a los sonorenses en la cúspide del poder.

Palabras clave: revolución mexicana; partidos políticos; elecciones; Salvador Alvarado; Álvaro Obregón.

* Agradezco a la doctora Georgette José por su guía en la elaboración de este trabajo, así como por todo su apoyo y generosidad en mi formación como historiador. Asimismo agradezco el soporte continuo de Karina Villegas Terán. 
Abstract: This article highlights one of the lesser known facets of General Salvador Alvarado: his role in the presidential succession of 1920. Through a review of unexplored sources such as the El Heraldo de México and El Monitor Republicano newspapers, it sheds light on the complexity and tension of the political context of the election. Alvarado modified his position as time went by, from a belligerent attitude that led him to create his own political party against Generals Pablo González and Alvaro Obregón, to an alliance with the Sonora-based group struggling against the imposition of the Carranza-backed candidate, Ignacio Bonillas. In addition to describing Alvarado's interest in the presidency, this article shows the role of Mexico City's newspapers as spaces for discussion and driver of political platforms in the elections that swept the Sonoran group to power.

Key words: Mexican revolution; political parties; elections; Salvador Alvarado; Álvaro Obregón.

Fecha de recepción: 30 de noviembre de 2016 Fecha de aceptación: 17 de enero de 2017

\title{
EXORDIO
}

\begin{abstract}
A 1 iniciar 1919 una de las preguntas más relevantes en el ámbito políti- 1 co mexicano era ¿quién sería el próximo presidente? Las elecciones se acercaban y dos generales de división eran los principales candidatos: Álvaro Obregón y Pablo González. La contienda parecía resumirse a la lucha entre los dos militares que mayor prestigio habían adquirido durante y después del triunfo carrancista de 1915 frente a los ejércitos convencionistas. El presidente Venustiano Carranza apostó por una tercera opción, el entonces embajador de México en Washington, el ingeniero sonorense Ignacio Bonillas; un personaje desconocido en el país, pero leal a Carranza desde la lucha contra Victoriano Huerta en 1913 (Matute, 1980).

No obstante, detrás de estos sobresalía una cuarta opción, la del general Salvador Alvarado. La historiografía no ha abordado lo suficiente esta etapa de la vida del sinaloense; su gubernatura en Yucatán y su posterior anexión a la rebelión delahuertista son los espacios más comunes para hablar del divisionario. ${ }^{1}$ ¿Alvarado pensó en buscar la presidencia?, ¿qué estrategias

${ }^{1}$ Joseph (1992) sólo da pistas de las aspiraciones de Alvarado cuando llegó a Yucatán en 1915: "quizá viera incluso la península como una plataforma para la presidencia nacional"
\end{abstract}

\section{()(1) $\$$}


llevó a cabo para ganar terreno en el ámbito político? Ambas preguntas serán el hilo conductor de este artículo.

En enero de 1919 cuatro eran los principales periódicos de la ciudad de México: El Universal de Félix F. Palavicini; Excélsior, dirigido por Rafael Alducin; El Pueblo, cuyo encargado era Gregorio A. Velázquez, pero pronto salió del panorama periodístico (desapareció el 15 de mayo), y El Demócrata, fundado por Rafael Martínez "Rip-Rip", controlado por el secretario de Gobernación Manuel Aguirre Berlanga.

El gobierno carrancista tenía bajo su control a El Demócrata y a El Pueblo. El Universal era el periódico con mayor producción al tirar 35000 ejemplares diarios. Al iniciar la polémica electoral se mostró ligeramente favorable al general Pablo González, pero con el transcurrir de los meses aseguró su neutralidad y publicó opiniones contra Obregón. Excélsior era el segundo órgano informativo más importante, impulsó la postura "civilista" que buscó crear el régimen carrancista para desprestigiar a los generales pretendientes a la silla presidencial (Matute, 1980, pp. 13-14).

Sin embargo, este panorama se complejizó en abril del mismo año gracias a la aparición de dos periódicos: El Heraldo de México, creado por Alvarado en abril de 1919, y El Monitor Republicano, órgano de propaganda del Partido Liberal Constitucionalista (PLC). El primero de ellos ofrece un espacio poco esclarecido hasta ahora: la creación de una plataforma política para proponer a otro candidato que compitiera en las elecciones de 1920. El Monitor Republicano y el periódico alvaradista fueron los espacios de discusión de diversas agrupaciones políticas de la época, y reflejaron una dinámica electorera no explicada lo suficiente entre el propio pLC y el Partido Liberal Democrático (PLD), impulsado por Alvarado.

Este artículo aborda la carrera del general Salvador Alvarado por formular otra candidatura o bien alcanzar él mismo la silla presidencial. Se analizará la transformación de sus tendencias y anhelos en la coyuntura electoral, de una postura belicosa contra los otros candidatos, a una alianza con el grupo sonorense. Decidimos realizar un análisis de la prensa como medio difusor en el contexto de las campañas electorales y su opinión con respecto a los candidatos y las elecciones de 1920. Se pondrá acento en la re-

(p. 126). Marisa Pérez (2016) recientemente ha explicado el proceso de la península yucateca antes de la llegada de Alvarado. Sobre la rebelión delahuertista Alonso Capetillo (1926), Georgette José (1998 y 2014) y Enrique Plasencia (1998). Sin duda alguna, el estudio introductorio de la antología sobre Alvarado de Paoli (1994) es el texto que ofrece más elementos para comprender este periodo de la vida de Alvarado.

\section{()(1) $(3$}


visión del emisor y de los contenidos de sus publicaciones, vinculándolos en todo momento con el contexto general (Pizarroso, 1999, p. 159).

La prensa de la revolución mexicana ha sido el centro de atención de diversos especialistas en los últimos años (Garciadiego, 1995; Ramírez Hurtado, 2010; Serna, 2007, 2014); el vínculo de esta con los procesos electorales durante y después de la revolución mexicana es una tarea pendiente que permitirá comprender la construcción de campañas políticas, de redes y alianzas entre los principales actores en un periodo en donde los partidos políticos estaban por debajo de los caudillos, pues el ejército era el factor más trascendental del sistema político mexicano. ${ }^{2}$

\section{UNA RELACIÓN ACCIDENTADA: SALVADOR ALVARADO Y ÁLVARO OBREGÓN}

Salvador Alvarado Rubio nació en Culiacán, Sinaloa, el 16 de septiembre de 1880, no obstante, cuando tenía ocho años su familia se mudó a Pótam, Sonora, por lo que su periodo formativo lo vivió en este estado (Paoli, 1994, p. 14). Tuvo una densa carrera revolucionaria, la inició prácticamente desde los albores del siglo $\mathrm{xx}$, fue probablemente magonista, maderista y constitucionalista. En 1915 su vida dio un giro inesperado cuando Carranza lo designó jefe militar de la región sureste -comprendía los estados de Tabasco, Campeche, Yucatán, Chiapas y el territorio de Quintana Roo- para derrotar al líder henequenero Abel Ortiz Argumedo. Una vez que tomó el control de la región, puso en práctica sus ideales sociales modernizadores y obtuvo reputación política en la península yucateca (Joseph, 1992).

En 1919 Alvarado aparecía como "el hombre fuerte" de Yucatán, lugar a donde exportó la revolución: "El prestigio adquirido le valió para gobernar Yucatán con mano dura, en una especie de socialismo, todo lo cual permitió la destrucción de monopolios henequeneros a través de la Reguladora del

${ }^{2}$ Existen varios estudios sobre las diversas campañas y sucesiones presidenciales que han utilizado a la prensa como fuente $y$, en ocasiones, como objeto de investigación: la contienda de 1920 ha sido explicada por Matute (1980); la campaña de Plutarco Elías Calles (19231924) ha sido analizada con precisión por Georgette José (1998), en 2012 la misma autora coordinó una obra sobre las elecciones de 1867 a 2006; González Marín (2006) revisó la coyuntura electoral que llevó a Ávila Camacho a la silla presidencial. En los últimos años Fausta Gantús y Alicia Salmerón han impulsado la historia electoral decimonónica y su vínculo con la prensa (Gantús y Salmerón, 2014; Gantús, 2015; Gantús, 2016).

\section{()(1) $\$$}


Henequén, compañía que manejaba él mismo [...]. Quizá después de González, el más presidenciable de los generales era Alvarado" (Matute, 2002, pp. 140-141).

El trato entre Alvarado y Venustiano Carranza sufrió cambios importantes en 1917, al iniciar la presidencia de este último, en gran medida porque Alvarado no ocupó la gubernatura constitucional de Yucatán -ni siquiera pudo lanzar su candidatura- por no ser nativo del estado, ni tener cinco años viviendo en la entidad (Joseph, 1992, p. 143). En febrero de 1918 se convocó a elecciones y triunfó el aspirante del Partido Socialista de Yucatán Carlos Castro Morales, líder de un sector ferrocarrilero y cercano a las políticas carrancistas (Paoli, 1994, p. 43).

Sin cargo público alguno, Alvarado terminó la redacción de su libro Mi actuación revolucionaria en Yucatán, y en agosto de 1917 se trasladó a Oaxaca para tomar las riendas de la jefatura de operaciones militares de Chiapas, Tabasco, el istmo (distritos de Juchitán, Tehuantepec y Choapam del estado de Oaxaca) y parte del sur veracruzano para combatir el movimiento liderado por el general Félix Díaz, quien había regresado al país proveniente de Estados Unidos (Paoli, 1994, p. 43). Después de enfrentar los brotes felicistas en el sureste mexicano, fue dejado en disponibilidad en el ejército; lo sustituyó el general Alejo González (Matute, 1985, pp. 161-164).

Cansado de la lucha armada, Alvarado buscó una vida más relajada y en marzo de 1919 se mudó a la colonia Roma de la ciudad de México. En su nueva residencia se dedicó a la redacción final de su libro La reconstrucción de México, en el que plasmó sus propuestas de reformas sociales y refutó algunas de las críticas a las que habían sido sometidas sus políticas reformistas en la península yucateca (Paoli, 1994, p. 43). ${ }^{3}$

El sinaloense siempre afirmó que no entraría a la disputa por ocupar la silla presidencial en 1920, no obstante, comenzó a cuestionar la situación en la que México se encontraba tras concluir la lucha armada, sobre todo porque las elecciones para definir al sucesor de Carranza se acercaban. Publicó sus propuestas gobiernistas en La reconstrucción de México, obra dividida en tres tomos. En el primero se enfocó a analizar diversos problemas: la mala administración de los recursos naturales (subrayó el caso del petróleo), el agrario, la crisis económica, la deuda pública y diversos tópicos de la economía internacional y la diplomacia. En el segundo se encargó de estudiar los problemas sociales, entre los que se encontraban las diferencias de clase, la educación y

${ }_{3}$ El Heraldo de México, 15 de agosto de 1919, p. 3.

\section{()(1)(3)}


la situación de la mujer. El tercero lo dedicó a diversos aspectos de índole política como el ejército, la cuestión laboral, el problema urbano, la problemática electoral, la libertad municipal y llamó la atención sobre la necesidad de reorganizar casi en su totalidad el gobierno mexicano. Su incomodidad con respecto a la situación mexicana resultó evidente (Paoli, 1984, pp. 182-183).

Por esos mismos días, el 27 de abril de 1919, se publicó por primera vez el diario El Heraldo de México bajo la dirección del ingeniero Modesto C. Rolland y el financiamiento del general Salvador Alvarado. ${ }^{4}$ La fundación de un periódico no le era desconocida a Alvarado, pues días después de su arribo a Yucatán creó $L a$ Voz de la Revolución, que comenzó a publicarse el 25 de marzo de 1915 en las instalaciones de La Revista de Yucatán; su director fue Antonio Ancona Albertos. Lo anterior no sólo lo dotó de experiencia para crear un órgano de difusión impreso, sino también lo llevó a conformar un grupo de trabajo que aparecería, años después, en El Heraldo (Paoli, 1984, p. 63).

El periódico surgió para difundir las ideas revolucionarias alvaradistas, reflejó las posturas de La reconstrucción y sus aspiraciones políticas en los comicios a efectuarse en julio del siguiente año. ¿Alvarado en realidad no aspiraba a ocupar la silla presidencial? El diario y su libro parecían demostrar lo contrario.

Los rumores dentro de los círculos políticos afirmaron, poco antes de que hiciera su aparición el órgano de propaganda del PLC - de forma no oficial el partido más cercano a Obregón-, El Monitor Republicano, ${ }^{5}$ que dicho periódico se enfrascaría en una lucha informativa con El Heraldo de México porque Salvador Alvarado y Álvaro Obregón ni siquiera podían verse cara a cara. Aseguraba Mario Méndez, director de Telégrafos, que cuando los periódicos ya estuvieran "bien AGARRADOs, saldrán ellos [los hombres cercanos a Carranza] con un candidato civil que será la tabla de salvación entonces. Ya se ve que con hombres tan atrasados así en política, no hay que

${ }^{4}$ Tuvo como directores al ingeniero Modesto Rolland, al poeta Antonio Mediz Bolio y al ingeniero Vito Alessio Robles, entre sus colaboradores destacaron Martín Luis Guzmán, el joven Manuel Gómez Morín y el caricaturista Santiago R. de la Vega.

${ }^{5} \mathrm{Su}$ director fue Basilio Vadillo, el coronel Miguel A. Peralta fue nombrado gerente y Luis Sánchez Pontón jefe de redacción. Entre sus colaboradores destacaron miembros de peso en el PLC como Enrique Colunga, Roque Estrada, Manuel García Vigil, José I. Lugo, Rafael Martínez de Escobar, Aurelio Manrique Jr., Eduardo Neri, licenciado José I. Novelo, José Siurob, Luis L. León, Manuel Mestre Ghigliazza, así como los exiliados José Vasconcelos y Antonio I. Villarreal. El rotativo desapareció en abril de 1920 en el contexto de la rebelión aguaprietista y reapareció en agosto del mismo año para llevar a cabo la propaganda pro-Obregón. Dejó de publicarse de manera definitiva los primeros días de septiembre del mismo año.

\section{(ㄷ)(1) $(3$}


temer, aunque sí deben tomarse precauciones." ${ }^{16}$ La realidad no se diferenció demasiado de lo que se planteaba a mediados de julio de 1919; los periódicos en cuestión se vieron inmiscuidos en diversas polémicas, relacionadas principalmente con las propuestas de Alvarado y Obregón.

Antes de adentrarnos en estas discusiones, es importante preguntarnos, ¿por qué se afirmaba que Obregón y Alvarado ni siquiera podían verse?, ¿cuál era la relación entre ambos generales?, ¿Alvarado buscaba una revancha política en 1920? En este punto comprenderemos algunas de las motivaciones de Alvarado para competir, ya fuera como candidato o no, en los comicios de 1920.

El trato entre Obregón y Alvarado fue tenso desde que se conocieron, sobre todo después de la lucha contra el orozquismo en 1912, momento en que Obregón, presidente municipal de Huatabampo, organizó el $4^{\circ}$ batallón de fuerzas irregulares. Terminada la lucha antiorozquista, el sonorense volvió a Hermosillo con el grado de coronel, "su prestigio había subido como la espuma para escozor de algunos jefes de mayor jerarquía hasta entonces, como Salvador Alvarado, cuyo rango de mayor permaneció estable pese a sus servicios en la misma campaña" (Aguilar, 1986, p. 268), además el sinaloense contaba con una carrera revolucionaria más larga que Obregón, quien no había participado en la asonada maderista.

Al iniciar la lucha contra Huerta, el gobernador de Sonora Ignacio L. Pesqueira, dividió en tres sectores el estado otorgando jefaturas militares a cada uno de ellos: en el norte Juan G. Cabral; en el sur Benjamín Hill; en el centro Salvador Alvarado; quien ascendió a teniente coronel el 1 de marzo y a coronel el 5 del mismo mes de 1913. Sin embargo, el nombramiento más importante, la jefatura de la sección de guerra, fue ocupada por Obregón (Aguilar, 1986, p. 288).

Durante la batalla de Santa Rosa, Sonora, a principios de mayo de 1913, Obregón había prescindido de Salvador Alvarado para continuar el avance hacia el sur. No obstante, la emboscada contra el Ejército Federal que había planeado el jefe de guerra en dicha plaza no funcionó y fue necesario el arribo de Alvarado, quien se encontraba en Hermosillo, su llegada fue clave para obtener la victoria. ¿Por qué lo había dejado fuera de esa fase de la campaña? No lo había hecho por dudar de sus aptitudes militares, sino por su "abierta animosidad [...], su indisciplina y convicción altanera de que Obre-

${ }^{6}$ Trinidad W. Flores a Roque Estrada, 21 de julio de 1919. En Matute (1985, p. 51). Las mayúsculas son del original.

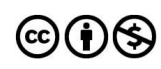


gón no tenía más méritos que él para ocupar el sitio que ocupaba" (Aguilar, 1986, p. 340).

Esta rivalidad no disminuyó con el transcurrir de los meses, sino todo lo contrario. El triunfo en Santa Rosa los llevó a ambos a obtener el grado de general brigadier, sólo debajo del gobernador Pesqueira. Los triunfos comenzaron a caer con gran velocidad, después de Santa Rosa vino Santa María y más adelante la decisión de llevar a cabo un cerco sobre Guaymas, en donde salió a relucir más que nunca la animadversión entre ambos mílites. Los constantes conflictos de liderazgo impulsaron a Obregón a dejar estático a Alvarado "en Sonora al frente de las fuerzas yaquis que no querían salir del estado, cuidando el puerto inerte, mientras él se dirigía al sur sin esa sombra competitiva y molesta que tantos conflictos le había provocado" (Aguilar, 1986, p. 352).

Obregón se distanció de Pesqueira, quien vio de mala manera que no fuera tomada la plaza de Guaymas y sólo se cercara, pero la coyuntura política de nuevo favoreció al sonorense cuando estaba a punto de ser separado del mando militar del ejército del noroeste (Alarcón, 2008, p. 243). Maytorena regresó y Álvaro Obregón pactó con él para mantener su liderazgo y debilitar a los otros hombres fuertes de la región. Cuando el ejército del noroeste triunfó en Jalisco y Obregón preparaba su arribo a la ciudad de México, Maytorena -en el contexto de su nueva alianza con Villa-ordenó la aprehensión de Alvarado, quien fue enviado a la cárcel de Hermosillo (Aguilar, 1986, p. 409; Alarcón, 2008, p. 295).

Una vez que Alvarado recuperó su libertad por lo acordado en la Convención de Aguascalientes con respecto a liberar a todos los presos políticos de las distintas facciones en pugna, se dirigió a la ciudad de México y se unió al bando carrancista. El 25 de noviembre de 1914 fue designado comandante militar de la capital y al siguiente día también se le nombró jefe de la línea ferroviaria Veracruz-Puebla-Tlaxcala, cargo que desempeñó hasta el 10 de enero de 1915 (Paoli, 1994, p. 27). Obregón, con una actitud indecisa, finalmente decidió enfrentar la nueva guerra del lado del Primer Jefe, quien le encomendó la tarea de conformar el ejército de operaciones que debía batir a las huestes convencionistas, principalmente al ejército villista. El general Alvarado concentró un importante número de hombres para enfrentar a los zapatistas en Puebla, no obstante, los sureños lo derrotaron y abandonó la plaza a mediados de diciembre de 1914.

Debido a la derrota alvaradista, Obregón llegó de Veracruz y reforzó con 5000 hombres al bando carrancista, la vida volvió a unirlos en una lu-

\section{()(1) $(9$}


cha. Finalmente la plaza fue recuperada por los carrancistas en los primeros días de enero de 1915. Carranza entendió muy bien la enemistad entre ambos militares y decidió darle un giro a la carrera de Alvarado, quedó al mando del ejército del sureste que abarcaba Tabasco, Campeche, Chiapas, Yucatán y el territorio de Quintana Roo. Su nueva misión sería "llevar" la revolución a Yucatán, en donde poco después logró consolidar su gobierno sostenido económicamente por el henequén. Alvarado no "tomó con entusiasmo" este nombramiento y sintió una vez más que el sonorense lo excluía del campo de batalla. Su nueva tarea fue "más administrativa que militar" (Paoli, 1994, p. 28). Paralelamente, Obregón se convirtió en el militar de mayor renombre dentro del ejército carrancista, derrotó a Pancho Villa, perdió un brazo en batalla, lo que le dio tintes de mártir, y fue el único general revolucionario invicto. La enemistad y el recelo fueron las características de la relación entre estos dos militares, además entendían la lucha armada desde sus respectivas trincheras, el sonorense era pragmático, un pequeño propietario, el sinaloense un estadista con ideas más radicales.

\section{CONSTRUYENDO UNA CANDIDATURA, ¿ALVARADO UN PRESIDENCIABLE?}

Al iniciar la pugna presidencial, Salvador Alvarado -como era de suponerse- no apoyó la candidatura de Obregón e, incluso, El Heraldo de México pidió al sonorense replantear su manifiesto del 1 de junio de $1919,{ }^{7}$ pese a que algunos puntos del texto coincidían con las críticas del propio diario hacia la situación política imperante, como lo era el fracaso y ruptura del Partido Liberal debido a su indisciplina y alejamiento de los ideales revolucionarios.

En su obra La reconstrucción de México, Alvarado arremetió contra el manifiesto de Obregón. Allí aseveró que

la elaboración de una "MANifiestación Al pUeblo", de una "proclama" o de un "PROGRAMA DE GOBIERNo", como todos los conocidos, calcado en los que han sufrido tan hondo desprestigio, es obra de poco momento: la literatura de esos documentos insubstanciales y que a nadie engañan ni mucho menos convencen [...] (Alvarado, 1919, t. I, p. 129. Las mayúsculas aparecen en el original).

${ }^{7}$ El Heraldo de México, 9 de junio de 1919, p. 1.

\section{(1)(1) $\$$}


Era necesario "concederles la jubilación por inútiles". Estas palabras fueron sólo el inicio de una abierta actitud belicosa de Alvarado.

El Heraldo criticó el manifiesto en su totalidad. La tendencia del diario fue de absoluto rechazo hacia el texto obregonista debido a "su anacronismo, espíritu antidemocrático y poco republicano" que sólo "periódicos venales podían defender". ${ }^{8}$ La polémica periodística entre obregonistas y alvaradistas encontró aquí su inicio.

El 13 de agosto de 1919 Alvarado escribió una carta abierta dirigida al presidente Venustiano Carranza, y a los generales Pablo González y Álvaro Obregón a través de la que buscó conciliar las diversas posturas políticas, pero al mismo tiempo trató de fortalecer su propia campaña y consolidar una base de apoyo iniciada meses atrás. En la epístola resumió los principales preceptos plasmados en su obra La reconstrucción de México. Alvarado los exhortaba a reflexionar sobre los problemas que aquejaban al país: la pacificación, el ejército, la administración de justicia, la cuestión agraria y obrera, las deficiencias educativas, la banca, el "peligro de la contienda electoral y la división del Partido revolucionario".

Los argumentos de Alvarado estaban encaminados a poner énfasis en la organización de una convención revolucionaria para designar un candidato que no tuviera grado de general de división, y de esta forma no surgieran problemas entre los líderes revolucionarios; todo ello con el fin de iniciar la "reconstrucción" nacional. Sin embargo, aseveró que "la división de nuestro Partido se está consumando y como consecuencia inevitable se han formado dos fracciones personalistas que sostienen a sus respectivos candidatos, y que están dispuestos a entablar una estéril lucha, llena de desahogos y apasionamientos, cuyo final acarreará grandes males a la Nación”. ${ }^{9}$

El sinaloense llamaba la atención a la necesidad de que se llevaran en orden los comicios federales de 1920. Para ello pedía el apoyo de Carranza y conminaba a los candidatos a abandonar su ambición presidencial:

si mis esperanzas no son vanas y mis antiguos compañeros de armas los generales Obregón y González aceptan mi proposición, deberán renunciar a sus respectivas candidaturas a la Presidencia de la República y como ellos cualquier otro general de División a quien se le proponga su postulación, pues el objeto de unificar los trabajos del grupo revolucionario y de todos los hombres de bue-

${ }^{8}$ El Heraldo de México, 3 de julio de 1919, p. 3.

${ }^{9}$ El Heraldo de México, 15 de agosto de 1919, pp. 3-4.

\section{()(1) $(9$}


na fe, de voluntad y de carácter, no es reñir por alcanzar el poder, sino reconstruir el país y salvarlo de los graves e inminentes peligros que lo amenazan. ${ }^{10}$

Una vez conformado el "Gran Partido" las elecciones se verificarían de la forma más pacífica. Alvarado creía que la mejor opción era un candidato civil que aceptara un proyecto de nación ya discutido y elegido por la convención de revolucionarios. ¿Acaso una convención revolucionaria era la vía apropiada para impulsar una nueva candidatura? Habían transcurrido cinco años desde el intento fallido en Aguascalientes, pese a que la situación militar en el país distaba mucho de lo acaecido entre 1914 y 1915, parecía algo utópico concretar un programa de gobierno y elegir un candidato civil en una junta de revolucionarios, sobre todo porque gran parte de la legitimidad de los hombres dependía todavía de su accionar en la lucha armada recién concluida y las posturas personalistas cobraban gran fuerza con el transcurrir de los meses al acercarse la fecha de los comicios.

El personaje que Alvarado tenía en mente para ser candidato a la presidencia "pudo haber sido don Adolfo de la Huerta, aunque nunca lo aclaró" (Paoli, 1994, p. 44). En la misma carta abierta insistió que no "aceptaría bajo ningún motivo" su candidatura, pues sólo bajo este método el país estaría más cerca de su madurez democrática, como ya lo había asentado en La reconstrucción (Alvarado, 1919, t. III, p. 323). ¿Por qué De la Huerta era una opción para Alvarado?

Su relación con De la Huerta era cordial y sus pasados revolucionarios se entrelazaron desde los primeros años del siglo xx. Alvarado y De la Huerta se conocieron desde 1903 cuando ambos vivían en Pótam, población cercana a Guaymas, Sonora. Estudiaron juntos, platicaron sobre los problemas de su época e incluso Alvarado le pidió ayuda a De la Huerta para obtener un mejor empleo que el que tenía como ayudante de su padre en el comercio de pieles; al parecer el joven Adolfo le consiguió uno en Guaymas (Guzmán, 1957, p. 70; Paoli, 1994, p. 14). Al dejar la gubernatura de Yucatán, el general Alvarado recomendó a Carranza que De la Huerta fuera el "moderador" de las fuerzas del estado antes de que se efectuaran las elecciones para gobernador; el presidente aceptó y el sonorense tranquilizó las tensiones políticas antes de que Carlos Castro Morales se encargara del estado (Castro, 1998, pp. 17-18). Su amistad persistió hasta 1924, en el contexto de la rebelión delahuertista.

${ }^{10}$ El Heraldo de México, 15 de agosto de 1919, p. 4.

\section{()(1) $(3$}


No obstante, Alvarado también pudo contemplar a otro personaje con quien tenía una relación amistosa desde 1913 y era un pilar del grupo carrancista, el secretario de Hacienda Luis Cabrera, quien incluso compró acciones de El Heraldo de México en marzo de 1920 y tenían una relación amistosa desde 1913. ${ }^{11}$ Dicha postura no pudo ser dada a conocer porque hubiera significado la ruptura absoluta con los sonorenses, específicamente con De la Huerta. Alvarado, político astuto y experimentado, jugaba y barajeaba sus cartas en la lucha electoral.

En el tercer tomo de La reconstrucción, Alvarado asentó que en México no existían partidos políticos organizados con principios y metas definidos. Debido a ello, se organizaban en plena coyuntura electoral y con tintes "personalistas", sin un programa de gobierno que respondiera al "pensamiento nacional". El resultado: la aparición de un régimen "ultrapersonalista” (Alvarado, 1919, t. I, pp. 122-123). Por ende, el candidato elegido debía ofrecer "mayores seguridades" y cumplir con el programa que se le imponía:

Cuando la obra de la inteligencia y del estudio, de la ciencia y del arte de gobierno, haya producido UN PROGRAMA POLÍTICo, del cual emane UNA PLATAFORMA DE GOBIERNO, busquemos a los hombres CAPACES DE REALIZAR ESA OBRA, y elevémosles al poder no por pasiones, ni por conveniencias ni por simpatías; sino porque RESPONDAN EN TODO a los altos fines del partido y a las más altas necesidades de colectividad (Alvarado, 1919, t. I, p. 129. Las mayúsculas aparecen en el original).

En este contexto Alvarado inició la creación de una nueva plataforma política, un partido político, ¿para ello había creado El Heraldo de México?, ¿en realidad se trataba de un periódico electorero disfrazado de uno de corte comercial-empresarial? La historiografía prácticamente ha descartado incluir a Alvarado en la pugna presidencial, cuando en realidad sus pretensiones eran un secreto sabido por todos los actores de la época.

Un mes después, el 12 de septiembre, Alvarado inició la creación de su agrupación política. Escribió una carta a Carranza en la que solicitó licencia absoluta del ejército para atender algunos asuntos particulares y formar un partido político de carácter nacional que tendría como objetivo principal "invitar a los mexicanos en general y a los revolucionarios en particular" a participar en las elecciones para que se llevaran a cabo "las reformas necesarias en

${ }^{11}$ El Heraldo de México, 24 y 27 de marzo de 1920, p. 1.

\section{()(1) $\$$}


nuestra organización política y evitar a toda costa la lucha entre dos partidos cuyos componentes son adictos a los Jefes militares que por la fuerza de las circunstancias envolverán al Ejército en la lucha electoral, con los desastrosos resultados que para el país traería tal contienda" (Fabela, 1973, vol. XVIII, pp. 296-297). Los trabajos se encaminaban a "unificar" al partido revolucionario y a someter las candidaturas a la decisión de una convención en donde se aprobaría el programa de gobierno, como lo había propuesto meses atrás. Carranza y el Senado dieron el visto bueno a la solicitud y Alvarado obtuvo su licencia absoluta del ejército el 1 de noviembre de $1919 .^{12}$

El 1 de octubre de 1919 El Heraldo de México destacó la constitución del Partido Liberal Democrático (PLD) llevada a cabo un día antes, en el número 1 de Reforma. El diario alvaradista también atacó al PLC, afirmando que había extraviado la senda revolucionaria. El propio Alvarado encabezó la comisión que elaboró los estatutos y el plan de acción del futuro partido. ${ }^{13}$

En el discurso inaugural Salvador Alvarado sentenció que sólo su partido podría evitar una crisis política en la sucesión presidencial y no a través de las "camarillas burocráticas" que existían en ese momento en la ciudad de México:

No es que yo niegue los grandes méritos contraídos ante la patria por el General Álvaro Obregón o por el General Pablo González, ni la razón que por ellos les asiste, sin duda alguna, para sentir aspiraciones al alto honor de sentarse un día en el solio presidencial de nuestra República; tampoco desconozco el derecho que tienen los amigos y simpatizadores de esos dos Jefes prominentes de la gran Revolución Constitucionalista, al igual que los de algunos otros de sus principales caudillos y estadistas para desear sus candidaturas a la Presidencia de la República o para empeñarse en propagar sus ideas y sostenerlas con todo apasionamiento; pero siempre he dicho que la forma con que desgraciadamente se han iniciado los trabajos electorales a favor de los señores Generales Obregón y González, nos llevarían directamente a la guerra civil. ${ }^{14}$

${ }_{12}$ El Heraldo de México, 4 de noviembre de 1919, p. 1.

${ }_{13}$ El Heraldo de México, 1 de octubre de 1919, p. 1. En la reunión se instaló el primer club del PLD en el Distrito Federal y quedó integrado de la siguiente manera: presidente, diputado José Ignacio Mena; vicepresidente, Alfredo Álvarez; secretario, ingeniero Atanasio Núñez; primer vocal, diputado Vito Aguirre, y segundo vocal, el periodista Luis Zamora Plowes (Paoli, 1994, p. 45).

${ }^{14}$ El Heraldo de México, 1 de octubre de 1919, pp. 1, 10.

\section{(이요}


Alvarado reiteró que no aspiraría a la presidencia de la república, criticó la futura convención nacional que organizarían los partidarios del PLC, y afirmó que "jamás" en la historia de los partidos políticos en México se había intentado llevar a cabo una labor tan "sincera" como la que él estaba proponiendo, ya que significaba la creación, por parte de los ciudadanos, de la plataforma política para un futuro gobierno democrático. ${ }^{15}$

El 12 de octubre se publicó en El Heraldo de México el "Manifiesto de la Junta Central Organizadora del Partido Liberal Democrático", firmado dos días antes, en el que se continuaba criticando el personalismo acendrado de las candidaturas existentes y se hacía un llamado al "pueblo mexicano" a alzar su voz e incluirse en la práctica política a fin de evitar el estallido de una nueva crisis. El PLD no contaba con un candidato presidencial determinado, eso no importaba, lo único que creían ineludible era desarrollar un programa que conjugara todas las necesidades de México: "No nos interesa en manera alguna el ciudadano que ocupe la primera Magistratura, con tal de que sea llevado al poder por un Partido Nacional de principios. Que le haya impuesto de antemano un programa que satisfaga las aspiraciones del país." ${ }^{16} \mathrm{Pe}-$ dían a los seguidores del PLD que no se postulara a Alvarado como candidato presidencial, pues se perdería el objetivo: luchar contra los personalismos. Es importante destacar que entre los firmantes, y como primer vocal, se encontraba Vito Alessio Robles, quien más tarde sería el director del propio Heraldo (Paoli, 1994, p. 45).

El 19 de octubre se publicó el "Programa del Partido Liberal Democrático" en el que se enlistaron básicamente los mismos puntos asentados desde el 30 de septiembre. "El PLD se planteaba en sus Estatutos como una federación de partidos liberales que se fundarían en cada estado de la Federación, los que serían completamente autónomos en cuanto a su régimen interior y también para decidir la política que seguirían en las entidades", ${ }^{17}$ su organización estaría basada en clubes. Finalmente, se propuso llevar a cabo la gran convención del partido durante la Semana Santa de 1920, a fin de elegir al candidato presidencial (Paoli, 1994, pp. 45-46).

¿Realmente era realizable un proyecto de esa envergadura? Sin duda, el planteamiento de Alvarado al tratar de establecer una federación de partidos con un accionar autónomo en cada entidad era poco viable, sobre todo por-

${ }^{15}$ El Heraldo de México, 1 de octubre de 1919, p. 1.

${ }^{16}$ El Heraldo de México, 12 de octubre de 1919, pp. 1-2.

${ }^{17}$ El Heraldo de México, 19 de octubre de 1919, pp. 1 y 12.

\section{()(1) $\$$}


que el propio Alvarado no era un personaje que pudiera conciliar a los grupos existentes; en esos años los partidos políticos dependían de los hombres fuertes, no al revés. No obstante, su idea era similar a la que meses más tarde llevó a cabo el Centro Director Obregonista (CDo), que involucró un amplia gama de partidos, grupos y clubes políticos. Obregón y sus hombres cercanos sí fueron capaces de aglutinar a los diversos grupos políticos. El proyecto de Alvarado sólo quedó asentado en el papel; en el momento que se debía llevar a cabo la convención del partido el general sinaloense ni siquiera se encontraba en el país, como se verá más adelante.

En el editorial "El programa de los obregonistas", El Heraldo afirmó que las candidaturas del general González y, sobre todo, la de Obregón, no tenían ninguna de las características necesarias para llamarse "movimiento político del pueblo". Lejos de eso, eran grupos personalistas formados por unas cuantas personas. Recalcaba la necesidad de crear un gran partido revolucionario con un programa definido por el sentir de la mayoría y no por el de Obregón. De ahí que el periódico lanzara varias preguntas a los partidarios del sonorense:

¿Qué sucederá, sin ir muy lejos, [si] el programa en proyecto, reflejo fiel de la voluntad política de un partido del pueblo mexicano, discrepara de las ideas políticas del general Obregón, candidato escogido antes de que los partidarios se pusieran de acuerdo sobre ideas de gobierno? ¿Renunciarán los obregonistas al programa? ¿O esperan, quizás, los obregonistas, hacer un programa que cuadre punto por punto con los propósitos gubernativos del general Obregón, con los propósitos de un hombre que no cree en los programas, según confesión escrita? ¿Y qué sucedería, asimismo, si el general Obregón, que según palabras muy suyas, quiere llegar al poder sin compromisos de ninguna especie, rehusara acatar las prescripciones del programa y reiterara, como única garantía de su administración, sus antecedentes personales? ¿Renunciarían al candidato ${ }^{18}$

La salida era clara: dejar de lado a las personas, sin importar quiénes fueran, y avanzar en la consolidación del partido que integrara a las mayorías.

Obregón se enteró de las críticas a su campaña a través de un partidario, quien lo mantuvo al tanto de la situación: "El Heraldo de México se declaró en contra del Manifiesto a la Nación de Obregón. Se enfrenta a los

${ }_{18}$ El Heraldo de México, 9 de octubre de 1919, p. 3.

\section{(이요 $\$$}


liberales de todo el país para que se reúnan y formen una convención bajo su égida y a la sombra de su empresa editorial, a fin de que de dicha convención surja ungido y autorizado el candidato del pueblo." ${ }^{19}$ Las respuestas a los ataques vertidos en las páginas de El Heraldo no tardaron en llegar.

El Monitor Republicano reaccionó y refutó los cargos que realizaba $E l$ Heraldo contra el PLC y el "funesto personalismo". Aseguraba el periódico que el diario de Alvarado no había escatimado en el uso de "vocabulario conservador" para atacar al Partido Liberal, adjetivos "que serían lógicos y explicables en los enemigos de la revolución Constitucionalista, cuya doctrina y cuyos destinos viene representando única y exclusivamente el PLC como agrupación nacional" ${ }^{20}$ Según el periódico, la convención organizada por Alvarado para buscar un tercer candidato había fracasado, e incluso aseguró que su fundador ni siquiera había asistido a la misma, cerca de las oficinas de El Heraldo, porque había mayoría del PLC.

El Monitor criticó la postura de Alvarado y su periódico, específicamente lo relativo a la conformación de su partido político. Desde el 19 de septiembre pronosticó el fracaso del llamado alvaradista para conformar el primer club del PLD un día antes en el local de Humboldt, número 39. El periódico obregonista aseveró que a la cita habían arribado gran cantidad de miembros peleceanos, pero Alvarado se negó a llevar a cabo la junta.

Lo anterior provocó que una comisión encabezada por el licenciado Miguel Alessio Robles, el profesor Urbano Lavín y Vicente Sparza Paz se trasladara a las instalaciones de El Heraldo de México con el objetivo de charlar con Alvarado. Alessio Robles se dirigió a este y le manifestó que había suficiente número de ciudadanos para instalar la junta y le pedía que pasara al edificio de Humboldt. "El general Alvarado, dando muestras de estar poseído del disgusto más vehemente, manifestó que él no concurriría a esa reunión porque en su concepto encerraba una 'patraña política', preparada por el Partido Liberal Constitucionalista y por el elemento obregonista", aseveró el periódico peleceano.

El cooperatista Jorge Prieto Laurens, uno de los asistentes, se mostró sorprendido por la actitud de Alvarado, quien reflejaba sus intenciones de ocupar la silla presidencial mediante una convención dominada por sus partidarios, por ello renunció a formar parte de la "camarilla alvaradista" reunida en el Comité Organizador del "Gran Partido Nacional". ¿Se trató de

${ }^{19}$ Carlos Félix a Álvaro Obregón, 1919. Citado en Serna (2007, p. 78).

20 El Monitor Republicano, 21 de septiembre de 1919, p. 3.

\section{()(1) $\$$}


una estrategia del PLC y de algunos miembros del Partido Nacional Cooperatista para impedir la creación de un nuevo partido o una simple mentira periodística para desprestigiar a la nueva agrupación? Al parecer el periódico peleceano exageró la labor de los miembros de su partido en la reunión para conformar el PLD, pero algo fue seguro: Alvarado observó detenidamente las dificultades a las que se enfrentaría en los siguientes meses si decidía lanzarse abiertamente a la lucha por la silla presidencial.

Después de los acontecimientos, los peleceanos inconformes decidieron redactar un acta de protesta que se incluyó en El Monitor Republicano:

Los suscritos, ciudadanos mexicanos en uso de sus derechos y atendiendo a la invitación pública dada a conocer por el "Heraldo de México" en su número de esta fecha, para asistir a una asamblea con objeto de fusionar a todos los elementos de buena voluntad y principalmente a los elementos revolucionarios con objeto de formar un Partido de Principios y dictar y discutir un programa de Gobierno, así como convocar a una gran convención nacional en la que se discuta y apruebe dicho programa y la candidatura para la presidencia de la república en el próximo periodo; en vista de la actitud inexplicable del ciudadano general Alvarado y de otro grupo de ciudadanos, principalmente de los que forman el Comité Organizador que ha convocado esta Asamblea, con excepción del C. Prieto Laurens que no quisieron asistir teniendo en cuenta que había en el seno de esta misma Asamblea una mayoría abrumadora de partidarios de los principios formulados por el Partido que postula al ciudadano general Álvaro Obregón para la presidencia de la República, demostrando con esta falta de asistencia que no tiene en realidad una amplitud de criterio y un deseo sincero de convocar a todos los ciudadanos sino solamente contar con aquellos que se presten a una maniobra política para contrarrestar la popularidad de la candidatura del ciudadano Obregón. ${ }^{21}$

Algunos de los firmantes acudieron a la redacción de El Monitor Republicano para pedir que se diera cabida en las páginas del diario a lo sucedido en las instalaciones de Humboldt. Prácticamente todos eran miembros del PLC.

${ }^{21}$ El Monitor Republicano, 21 de septiembre de 1919, p. 1. El documento fue firmado por Jorge Prieto Laurens, Miguel Álvarez del Castillo, Urbano Lavín, el general y doctor Enrique G. Osornio, los licenciados Rafael Martínez de Escobar, Miguel Alessio Robles, Juan T. Reynoso, Aurelio Manrique Jr., Abraham González Jr., Ignacio Ramos Praslow, José I. Lugo, entre otros.

\section{()(1) $\$$}


La misma nota del 19 de septiembre analizó el proyecto planteado por Alvarado que, según el diario obregonista, consistía en formar un partido político, no con elementos ajenos a los partidos o tendencias ya definidas, sino precisamente con ellos, aunque militaran en filas contrarias, para lograr "la fusión de los liberales y llevarlos a una Convención en la que fueran discutidos todos los candidatos que se presentaran a la Primera Magistratura del país". De ahí que, "actuando de buena fe", habían acudido miembros del PLC, del Cooperatista y de otros clubes instalados en el Distrito Federal. En pocas palabras, según el diario, el objetivo de la reunión era congregar a una nueva "camarilla" para lanzar la candidatura de Alvarado, pero debido a la "aplastante" mayoría peleceana decidieron no hacerla. Poco después de cancelado el encuentro, se congregaron 22 miembros cercanos a Alvarado en las oficinas de El Heraldo de México para constituir, en días posteriores, el comité organizador del partido.

Los editoriales de El Monitor se mofaron del supuesto antipersonalismo profesado por Alvarado y subrayaron el interés de El Heraldo por convocar a la reunión para conformar el comité del PLD a la que habían terminado asistiendo personas íntimas del sinaloense en las instalaciones del mismo rotativo. El diario se preguntaba

¿Cómo creer, así, en el líder de una Convención libre, si empieza por eludir la discusión con quienes no piensan como él y se refugia entre un grupito de adictos sobre quienes se sabe que ha de predominar sin duda alguna? ¿Quiere el general Alvarado una Convención de amigos únicamente? ¿Se trata de dar formalidades democráticas a un personalismo hipócrita para recordar las convenciones de los tiempos de Porfirio Díaz? ${ }^{22}$

Con esa actitud, según El Monitor Republicano, Alvarado denotó cierta inexperiencia política como organizador de un partido político, tratando de emular al PLC. Alvarado no consolidó nuevas alianzas, pues algunos regidores cooperatistas del Ayuntamiento de la ciudad de México, como Jorge Prieto Laurens, decidieron acercarse a las filas obregonistas o apoyar a Ignacio Bonillas. ${ }^{23}$ Desde ese momento Alvarado cambió su estrategia en la coyuntura electoral, comprendió que sin una base sólida no podría lanzar a su propio candidato u ocupar él mismo la presidencia.

${ }^{22}$ El Monitor Republicano, 21 de septiembre de 1919, p. 3.

${ }^{23}$ El Monitor Republicano, 23 de septiembre de 1919, pp. 1 y 10.

\section{()(1) $(3$}


El Monitor Republicano incluyó en sus páginas notas editoriales en busca de refutar lo que los partidarios de Alvarado difundían en las páginas de El Heraldo. Se le llamó "obsesivo" por intentar conseguir seguidores para su partido, pese a profesar su animadversión por el personalismo que veía encarnado en el PLC y su vínculo con Obregón. El PLD era la antítesis del PLC:

el general Alvarado ha caminado con éxito mezquino. Toda la orquesta sinfónica de su periódico, apenas si ha logrado atraer al seno del "Gran Partido Nacional" una concurrencia que sería para hacer llorar a un titiritero de aldea [...].

Pero no: también ha tenido el general Alvarado ocasión de que elementos serios y numerosos de la política militante se agrupen a su lado. Al convocar para la organización del Gran Partido, muchos de los del PLC estuvieron dispuestos a discutir con él sobre la sucesión presidencial. Eran elementos respetables, sanos, inteligentes; eran cifras de las que busca con empeño el general; pero... se le pusieron a la izquierda, reduciendo al divisionario a la mínima potencia, esto es, a la impotencia... Y esto no puede gustar al ex Gobernador yucateco ¡No faltaba más!...

Y ahí tenemos al divisionario -también visionario- sin poder, con su genio y todo, levantarse un centímetro más por encima de sus conciudadanos.

Y es que el genio pesa, pesa más que si se llevara, atadas a las piernas, mil pacas de henequén!... ${ }^{24}$

En el editorial "La sombría literatura de Alvarado, el PLC y la paz pública" se criticó el establecimiento de la Junta Organizadora del PLD y la "paranoia" del general sinaloense al afirmar que era inminente una nueva guerra civil debido al acendrado personalismo que defendían los candidatos y la posible negativa de cada uno de ellos para aceptar la derrota en las urnas. El Monitor hizo un llamado a sus lectores para no dejarse guiar por el pánico político. El verdadero peligro, para el periódico obregonista, no radicaba en el apoyo a Obregón, ni en su supuesto personalismo, sino en una posible candidatura oficial que en ese momento parecía tomar forma. Para el periódico peleceano, la junta organizadora del nuevo partido ni siquiera mencionaba esa posibilidad y, en vez de unir y alentar al pueblo mexicano, "fomentaba el terror". En cambio, el PLC y el "obregonismo" eran sinónimos de "la paz pública, asegurada por un triunfo unánime en las elecciones generales". ${ }^{25}$

${ }^{24}$ El Monitor Republicano, 23 de septiembre de 1919, p. 1.

${ }^{25}$ El Monitor Republicano, 13 de octubre de 1919, p. 3.

\section{()(1) $(3$}


En "El prodigioso descubrimiento de Alvarado", el periódico peleceano señaló la frase que Alvarado había enunciado en la junta del Comité Organizador del PLD: "No hay en la historia de los partidos políticos en México, otro ejemplo de que se hubiese intentado siquiera hacer algo tan amplio, tan sincero, $\tan$ liberal y tan cuidadosamente acabado como el plan que nos proponemos desarrollar." El argumento fue refutado porque "esos gastados convencionalismos de expedir programas y lanzar manifiestos y elegir hombres para los puestos públicos, todos esos son engaños, son burdas patrañas de políticos profesionales y de embaucadores de muchedumbres" ${ }^{26}$ Reutilizaba la argumentación que Alvarado había planteado en La reconstrucción contra el manifiesto obregonista del 1 de junio de 1919.

Días después, ante las constantes críticas publicadas en El Heraldo de México, se señaló el exacerbado protagonismo y personalismo de Alvarado; conductas que había destacado como factores que impedían la conformación de un país democrático en donde el pueblo eligiera al candidato que defendiera un programa adecuado a las necesidades nacionales. Además se mofaron de la figura del sinaloense: "Don Salvador solo, vale por todos los grupos políticos. Vale lo que la opinión pública vale. Don Salvador es la opinión. Don Salvador es el país. Don Salvador es el salvador de la patria ¡Ah, qué don Salvador!" 27

A finales de octubre, El Heraldo de México realizó una entrevista a Alvarado en la que el general hizo, en palabras del diario, una vez más "profesión de fe política" al no aspirar a la presidencia del país. No obstante, $E l$ Universal del día anterior había asegurado todo lo contrario: el sinaloense se encontraba completamente dedicado a impulsar su candidatura presidencial a través de su propio partido. La nota de El Heraldo testificaba que su retiro del ejército obedecía al deseo de dedicarse a la intensificación de los trabajos del PLD. Según Alvarado, nada podría impedir el conflicto armado, aunque él mismo parecía fomentarlo e impulsarlo, a menos que los generales Obregón y González "renunciaran a hacer trabajos en su favor y se comprometieran a velar, por la pureza del voto" ${ }^{28}$ En cuanto a su posible candidatura, Alvarado aseveró que jamás había tenido la intención de postularse ni de aceptar su postulación.

26 El Monitor Republicano, 15 de octubre de 1919, p. 3.

27 El Monitor Republicano, 6 de noviembre de 1919, p. 1.

28 El Heraldo de México, 30 de octubre de 1919, p. 1.

\section{()(1) $\$$}


Nos dijo que no ha desperdiciado ocasión para reiterar su inquebrantable resolución de no hacer trabajo alguno que tenga por fin su postulación ni a aceptar que se hagan esos trabajos por otras personas. Que entiende que las frecuentes noticias que han aparecido en la prensa, tiene por fin desvirtuar los nobles y desinteresados trabajos que está llevando a cabo el Partido Liberal Democrático [...]. ${ }^{29}$

El siguiente año, 1920, significó un viraje en la actitud de Alvarado.

\section{EL VUELCO ALVARADISTA}

Como se ha visto, en 1919 Salvador Alvarado tuvo una postura propia en lo relacionado con la futura sucesión presidencial; sin embargo, su partido y sus propuestas no tuvieron el eco esperado, sobre todo frente a la popularidad de Obregón e incluso del propio Pablo González, quien tenía gran apoyo de un sector del ejército. Es probable que Alvarado no haya alcanzado ni siquiera los 100 partidarios que establecía la ley electoral vigente para conformar un partido político (José, 1992, pp. 31-33).

A finales de diciembre de 1919, Alvarado aceptó su derrota política y la imposibilidad de competir por la presidencia de la república. Trinidad W. Flores escribió que algunos empleados del telégrafo habían entablado una conversación con el secretario particular del sinaloense y les había comentado que el general Alvarado estaba "triste" por el fracaso de sus gestiones, pues sólo había querido "pulsar la opinión pública respecto a él, y que si bien observó que en un principio le era desfavorable, creyó que andando un poco más cambiaría en su favor, pero al fin se convenció de lo contrario, y no estado de acuerdo con la política seguida por el señor Carranza, se puso al habla con el C. Obregón y está de acuerdo con él para ponerse de su lado en su oportunidad". ${ }^{30}$

Alvarado comenzó a posicionarse paulatinamente hacia el grupo del candidato sonorense. Ello lo llevó a cabo por sus vínculos con otros personajes, sobre todo por su amistad con el gobernador de Sonora Adolfo de la Huerta, mas no por plena convicción de apoyar a Obregón. Diversos factores

29 El Heraldo de México, 30 de octubre de 1919, p. 1.

30 Trinidad W. Flores a Roque Estrada, 24 de diciembre de 1919, en Matute (1985, p. 112).

\section{(ㅇ)(1) $\$$}


se combinaron para que se concretara dicha alianza, el primero de ellos fue su aprehensión al iniciar 1920.

En enero, Alvarado arribó a Estados Unidos; la razón del viaje y la forma en que llegó son poco claras. El Heraldo de México aseguró que el 11 de enero de 1920 Alvarado había partido a Estados Unidos, por la ruta de Veracruz a Tampico, a realizar la compra de nueva maquinaria y elementos tipográficos para el periódico. ${ }^{31} \mathrm{El}$ mismo diario publicó tres días después que había sido detenido, sin especificar las razones, en Rincón Antonio, Oaxaca, por los hombres del general Alejo González, en ese momento leal a Carranza y jefe de operaciones militares de la zona correspondiente a Chiapas y al istmo de Tehuantepec. ${ }^{32}$ Con el paso de los días se aseveró que el sinaloense había sido aprehendido premeditadamente y que ese hecho formaba parte de una serie de "persecuciones indignas" de los "enemigos", con motivo de las campañas presidenciales, censuradas en la prensa oficial. ${ }^{33}$

El Monitor Republicano coincidió con su colega alvaradista en lo relativo a que Alvarado sólo había viajado para adquirir nueva maquinaria para su diario, pero según el periodista peleceano, se la había ofrecido el gobernador de Tabasco, general Carlos Greene, a quien visitaría. ${ }^{34}$ Días más tarde se publicó un editorial en donde se rechazó el trato dado al general Alvarado y se aseguró que su aprehensión era "reveladora", pues denotaba la "extrema vigilancia" que se ejercía sobre los elementos revolucionarios y sólo confirmaba la "debilidad moral del gobierno". ${ }^{35}$ Según este periódico, el presidente Carranza y su gabinete temían un nuevo levantamiento armado.

La narración oficial de lo sucedido, dada a conocer en El Demócrata, fue muy diferente a lo publicado por El Heraldo y El Monitor. La primera versión de El Demócrata fue que Alvarado partiría a Estados Unidos, pero no había sido aceptado en dicho país debido a sus ideas "radicales" de reforma social. ${ }^{36}$ Cuando periódicos como El Universal, El Heraldo de México y El Monitor Republicano dieron a conocer la aprehensión del general sinaloense, El Demócrata

31 El Heraldo de México, 12 de enero de 1920, p. 1. La nota desmintió que Alvarado viajaría a Estados Unidos para buscar el apoyo de este país, según afirmaba El Demócrata.

${ }^{32}$ El Heraldo de México, 15 de enero de 1920, p. 1.

${ }_{33}$ El Heraldo de México, 16 y 17 de enero de 1920, p. 1.

${ }^{34}$ El Monitor Republicano, 18 de enero de 1920, pp. 1, 7. Desde diciembre del año anterior se hablaba de la necesidad de adquirir nueva maquinaria debido al crecimiento del rotativo, El Heraldo de México, 1 de diciembre de 1919, p. 1.

35 El Monitor Republicano, 20 de enero de 1920, p. 3. El mismo editorial fue reproducido un día después en El Heraldo de México.

${ }^{36}$ El Demócrata, 13 y 14 de enero de 1920, pp. 1 y 3.

\section{()ㅜ(1) $\$$}


dio una nueva versión del viaje; aseguró que Alvarado había partido al istmo de Tehuantepec para ponerse al frente de un "movimiento extremista" en Yucatán y contaba con 200 hombres armados. Sin embargo, afirmaba, de la misma forma que El Universal, que no había detalles de su aprehensión. ${ }^{37}$ Finalmente, sin ahondar en el tema, el periódico fiel a Carranza publicó que el dueño de El Heraldo de México había recobrado su libertad, de Rincón Antonio se dirigiría a Veracruz y de ese punto partiría a Nueva York. ${ }^{38}$

El 18 de enero El Heraldo publicó que Alvarado regresaría a la ciudad de México, no obstante, nunca volvió y fue trasladado a Puerto México bajo la supervisión de Alejo González. ${ }^{39}$ Finalmente, fue liberado y protestó por su "injustificada" detención..$^{40}$ El Universal subrayó la solución de la situación, descartó la supuesta rebeldía del general y celebró que hubiera sido puesto en libertad porque "para la generalidad del público el encarcelamiento del señor Alvarado no era sino el principio de una serie de persecuciones políticas enderezadas contra la prensa independiente" ${ }^{41}$

¿Para que realizó ese viaje Alvarado? No existen respuestas precisas, pero es probable que viajara a Tabasco para entrar en contacto con Greene y analizar la posibilidad de adherirse al movimiento anticarrancista liderado por los sonorenses; no obstante, fue descubierto y posteriormente detenido, y por ello partió del país.

El ingeniero Vito Alessio Robles escribió al director de Telégrafos Mario Méndez para cuestionar por qué los telegramas de la esposa del general sinaloense, Laura M. de Alvarado, no llegaban a su destino. Aseveraba el director de El Heraldo que los mensajes de prensa nunca se recibían completos aun cuando trataran asuntos de información sin interés oficial, "los jefes de las oficinas foráneas tienen instrucciones especiales de don Mario Méndez, para tachar todo aquello que a su juicio pudiera causar mala impresión en el caso de ser publicado por los diarios". ${ }^{42}$ La "censura" telegráfica se incrementó durante estos meses.

${ }^{37}$ El Universal, 16 y 19 de enero de 1920, p. 1; El Demócrata, 17 de enero de 1920, p. 1.

${ }^{38}$ El Demócrata, 22 de enero de 1920, pp. 1 y 6.

39 El Heraldo de México, 18 de enero de 1920, pp. 1, 8 y 20 de enero de 1920, pp. 1 y 8 . El periódico peleceano aseguró un día después que había sido conducido a Oaxaca, El Monitor Republicano, 21 de enero de 1920, pp. 1 y 4.

${ }^{40}$ El Heraldo de México, 22 y 23 de enero de 1920, p. 1.

${ }^{41}$ El Universal, 24 de enero de 1920, p. 3.

42 El Universal, 21 y 24 de enero de 1920, p. 1.

\section{()(1) $\$$}


Los telegramas de Flores coinciden con lo apuntado por El Heraldo y $E l$ Monitor en cuanto a la censura de la aprehensión de Alvarado:

Salió de aquí el general Alvarado y no llamó la atención; pero en Veracruz se le agregó, de incógnito, un inspector de Telégrafos. De Puerto México se recibió un mensaje en clave y desde luego se puso el presidente en comunicación directa con el jefe de las armas de Rincón Antonio; y todo el día estuvieron conferenciando hasta que dieron aviso de que el general Alvarado había sido detenido. ${ }^{43}$

El 24 de enero de 1920, Alvarado tomó el vapor Wacoutla acompañado de su esposa y se trasladó a Nueva York, en donde vivió varios meses (Taracena, 1992, p. 176). Más que un "exilio voluntario" en San Antonio, Texas (Paoli, 1994, p. 47), se trató de la expulsión de un revolucionario por el gobierno carrancista. Estos acontecimientos propiciaron la ruptura total de Alvarado con el presidente Carranza.

Un mes más tarde, el apoyo de Alvarado al movimiento anticarrancista fue evidente, incluso afirmó desde Nueva York que Obregón era la opción más viable para ocupar la presidencia de la república. ${ }^{44}$ En Estados Unidos seguramente tuvo contacto con otros revolucionarios anticarrancistas que realizaban propaganda pro obregonista. Alvarado pronto se convenció de que lo más lógico era aceptar la candidatura del sonorense, además veía con buenos ojos el retorno de los revolucionarios que estaban exiliados, pues eran necesarios para la "reconstrucción" del país (Alvarado, 1919, t. III, p. 139). ${ }^{45}$

Durante su estancia en Estados Unidos escribió varios ensayos que más tarde publicó como folleto en Nueva York bajo el título La traición de

${ }^{43}$ El mensaje de Trinidad W. Flores, con fecha del 19 de enero de 1920, también llamaba la atención para que se extremaran precauciones entre los obregonistas; sobre todo pidió que se cuidaran Hill, Obregón y Novelo: "advertimos que todavía, después de la aprehensión del general Alvarado, se seguirán cometiendo atentados. Y también advertimos que el presidente es ACONSEJADO POR sus achichincles, los ineptos encumbrados, los incondicionales depravados." Trinidad W. Flores a Roque Estrada, 19 de enero de 1920. En Matute (1985, p. 121). Las mayúsculas son del original.

${ }^{44}$ El Monitor Republicano, 18 de febrero de 1920, pp. 1y 4; El Heraldo de México, 18 y 20 de febrero de 1920, p. 1.

45 "Esos MEJORES DíAs están por llegar. Al iniciarse la reconstrucción de nuestro país, sobre las nuevas bases y según las nuevas orientaciones que ha dado el movimiento revolucionario; todos los expatriados deben volver a México, para que la Nación no se resienta de la falta de esos elementos que, con su capacidad intelectual y económica, están en el deber de prestar a México el Servicio social que de ellos se espera." Las mayúsculas aparecen en el original.

\section{(ㄷ)(1) $(3$}


Carranza. En los escritos confrontó al presidente, especialmente en "Quién es Venustiano Carranza”, del 10 de marzo de 1920, a sólo unos días de que Ignacio Bonillas llegara a la ciudad de México (21 de marzo). Criticó al gobierno carrancista por sus "nulas" reformas sociales y por la imposición de diversos gobernadores estatales, así como por involucrarse en los comicios locales, situación que sólo había provocado fracturas internas en el régimen y en los revolucionarios de antaño. En el segundo ensayo, "El presidencialismo en México", Alvarado señaló el poder excesivo de Carranza como presidente de México y subrayó que "imponía, además, a todos los senadores, diputados federales, gobernadores y diputados locales" (Paoli, 1994, p. 47).

Por esos mismos días, según El Heraldo de México Alvarado se encontró con Ignacio Bonillas en la ciudad neoyorkina. El diario aseveró que el sinaloense advirtió al ingeniero y embajador en Washington que no debía prestarse a ser juguete de algunos "círculos políticos corrompidos" que trataban de utilizarlo para "defraudar el voto popular en las próximas elecciones". No se dieron a conocer más detalles, pero el rotativo tuvo la tendencia de dejar como una incógnita si Bonillas aceptaría su candidatura presidencial. ${ }^{46}$

También en La traición de Carranza se incluyó una "Carta abierta" dirigida a Carranza, fechada el 3 de abril de 1920, semanas después de ver al ingeniero sonorense. En ella Alvarado aseveró que Bonillas no contaba con un partido político que lo apoyara para ocupar la silla presidencial: "en el país, señor, nadie lo conoce; esas agrupaciones de última hora formadas en varios Estados y en la Capital para postularlo, no son en realidad más que agrupaciones de empleados públicos que están ansiosos de ganar la benevolencia de sus superiores trabajando en lo que se les ha ordenado" (Alvarado, 1920, pp. 31-34). Juzgaba como una mala estrategia la imposición de un candidato desconocido que avivara la idea de que la democracia estaba prácticamente muerta en el país. ${ }^{47}$

"El porqué de la nueva Revolución" fue el último ensayo del folleto de Alvarado. Posiblemente se distribuyó en territorio mexicano durante la segunda quincena de abril de 1920, es decir, durante el momento más álgido de la lucha entre Carranza y el gobierno sonorense (Paoli, 1994, p. 47). En él, la postura era completamente favorable a Álvaro Obregón. Alvarado, no tenía otra opción:

${ }^{46}$ El Heraldo de México, 11 de marzo de 1920, p. 1.

${ }^{47}$ La carta fue publicada también en La Nación de Nogales, Sonora, el 20 de abril de 1920, sólo tres días antes de que se firmara el Plan de Agua Prieta (Taracena, 1992, p. 200).

\section{()(1) $\$$}


Lo único que se pretende es [sic] elecciones libres, para que así el país decida su suerte, entregando el Gobierno al hombre a quien considere más apto. Esto es lo que no ha querido aceptar Carranza y por eso, primero con su farsa de postular para la Presidencia de la República, por medio de sus empleados, al señor Bonillas, desconocido e impopular, y luego por medio de sus persecuciones y atropellos, ha provocado la guerra civil, para así evitar las elecciones y mantenerse en el poder. Si el Partido Liberal Constitucionalista presentó como su candidato al C. Álvaro Obregón, fue porque lo considera el más apto para el alto cargo de Presidente de la Nación y porque él representa las ideas progresistas del Partido; porque él implantaría las reformas, urgentemente reclamadas por el pueblo y que desde 1910 han constituido la bandera de la revolución. Se quiere establecer una administración eficiente y honrada que procure para el pueblo cultura y bienestar y que no se componga de un grupo de favoritos enriquecidos, insolentes y corrompidos, que no ven más que su provecho y a quienes nada importa el pueblo porque saben que a él le deben, sino que todo se lo deben a su amo y protector (Alvarado, 1920, pp. 36-37).

Por esos mismos días, Alvarado criticó las acciones del gobierno en el mitin obregonista llevado a cabo en Tampico, en donde el general Francisco Murguía y el coronel Orozco hicieron prisioneros a Manlio Fabio Altamirano, Rafael Martínez de Escobar y Aurelio Manrique Jr. Desde Monterrey dirigió un telegrama a las instalaciones de El Monitor Republicano:

monterrey, n. L., abril 4 de 1920. C. Presidente de la República. México D. F.

Cualesquiera que sean diferencias que en política interior nos dividan, creo de mi deber dirigirme a usted para rogarle, en nombre de nuestra patria, no permita usted se sigan cometiendo atentados contra los ciudadanos por el sólo hecho de opinar en asuntos públicos.

Acabo de regresar Estados Unidos donde me di cuenta triste opinión tiénese de nosotros y las tremendas corrientes intervencionistas robustecidas últimamente motivo lucha electoral.

Señor Presidente, única forma evitar humillación es que elecciones y transmisión poder sean pacíficas. Usted debe esto a su raza, a su patria y a su nombre. Todavía es tiempo. Respetuosamente.

SALVADOR ALVARADO ${ }^{48}$

${ }^{48}$ El Monitor Republicano, 8 de abril de 1920, p. 1.

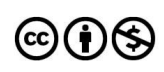


El 9 de abril la legislatura del estado de Sonora rompió relaciones con el ejecutivo federal (Cumberland, 1975, p. 369). La "revuelta" en Sonora fue cubierta en las páginas de $E l$ Heraldo desde mediados de abril. Destacó la forma en que los "insurrectos" se habían apropiado de las aduanas, del ferrocarril y habían batido a los federales. El 13 de abril se publicó un resumen de la situación en el estado, la nota sentenciaba: "Se esperan graves acontecimientos." ${ }^{49}$

Al día siguiente, 14 de abril, el periódico insistió en que la rebelión era "inquietante", pero destacó la inclusión en el movimiento del propietario de la Compañía Editorial Mexicana Salvador Alvarado, quien se encontraba en Estados Unidos pero había regresado al país para integrarse a las filas sonorenses.

Ayer circularon en esta ciudad persistentes rumores sobre que el general Salvador Alvarado se encuentra ya al lado de las autoridades sonorenses que desconocieron al Gobierno, y que prácticamente, es el director del movimiento. Estas noticias parecen confirmarse por los informes traídos ayer del lado americano, y particularmente de San Antonio, en donde los periódicos publicaron la siguiente noticia. ${ }^{50}$

Es probable que se haya trasladado de San Antonio a Monterrey, pues en esta ciudad pronunció un discurso contra el gobierno de Carranza. Luis L. León aseguró que lo encontró por esos días en la ciudad neoleonesa, en donde le aconsejó "mucha prudencia", y juzgó como inapropiada la postura del gobierno de Carranza para impedir la campaña de Obregón al inmiscuirlo en el proceso del contrarrevolucionario Roberto Cejudo (León, 1987, p. 99).

El 23 de abril se firmó el Plan de Agua Prieta a través del que se aseguraba que Venustiano Carranza había violado la soberanía de los estados y se había opuesto a las aspiraciones presidenciales de los diversos candidatos independientes. Se estipulaba que Carranza debía dejar la presidencia y Adolfo de la Huerta sería nombrado jefe supremo del Ejército Liberal Constitucionalista. Una vez consumado el movimiento, se elegiría un presidente interino que llamaría a elecciones presidenciales y del Congreso de la Unión. "En menos de dos semanas, 107 oficiales del Ejército, dirigidos por Calles, firmaron el Plan de Agua Prieta, que basaba la destitución de Carranza por haber violado la soberanía del estado de Sonora" (Buchenau, 2013, pp. 9-10).

49 El Heraldo de México, 13 de abril de 1920, p. 1.

50 El Heraldo de México, 14 de abril de 1920, p. 1. 
De la Huerta nombró a Elías Calles jefe de Operaciones Militares en el estado, acompañado por el general Ángel Flores (Dulles, 1977, p. 29).

El levantamiento aguaprietista triunfó. La buena relación de Alvarado con el presidente interino Adolfo de la Huerta lo vinculó nuevamente con Obregón y le acarreó un puesto en el gabinete, pues fue designado secretario de Hacienda. Como era de esperarse, su nombramiento no fue del agrado de Obregón, pero De la Huerta aseguró que era un hombre de su absoluta confianza, al ser "muy honorable, comprensivo y bien intencionado" (Alessio, 2010 , t. II, p. 63).

\section{PARA CERRAR}

Como se pudo observar, el caso del general Salvador Alvarado es una de las aristas poco cuestionadas por la historiografía de la revolución mexicana, sus aspiraciones presidenciales han sido ignoradas o descartadas. El sinaloense buscó consolidar una base política que le permitiera figurar en las elecciones de 1920 a través de El Heraldo de México, ya fuera como organizador de una agrupación política, el PLD, que creara un programa de gobierno y buscara el candidato idóneo para llevar a buen puerto los postulados de dicho plan, o apareciendo él mismo como candidato presidencial, cuestión que siempre negó.

Los sucesos al iniciar enero de 1920 lo orillaron a huir a Estados Unidos, su endeble plataforma política y la falta de apoyo llevaron a Alvarado a crear una nueva estrategia: apoyar al grupo de los sonorenses desde Estados Unidos contra la imposición de Bonillas y al mismo tiempo aliarse con un miembro del gabinete de Carranza, Luis Cabrera, secretario de Hacienda. A través de su diario capitalino Alvarado jugó sus cartas y tras el triunfo aguaprietista se integró al grupo sonorense (con el que había ascendido en la lucha armada desde 1913), en buena medida gracias a que su amigo Adolfo de la Huerta fue designado presidente interino de la república.

El giro alvaradista se concretó, pero su apoyo a la causa obregonista fue coyuntural, de corta duración, como lo demostró cuatro años después del asesinato de Carranza, en las campañas presidenciales de 1923-1924, cuando se unió al movimiento liderado por De la Huerta (José, 1998, 2012). Sus ideales revolucionarios contrarios al gobierno en turno y su enemistad con Obregón fueron tan marcados hasta el final de sus días que, luchando contra el sonorense invicto y la candidatura de Plutarco Elías Calles, encontró la muerte.

\section{()(1) $\$$}


Debajo de esta lucha personalista por la presidencia existió otro factor fundamental: el proyecto de gobierno de cada contendiente. Carranza creyó poder continuar su política poniendo en la lucha electoral a uno de sus hombres: el ingeniero Bonillas. Con lo anterior perdió de vista que su propuesta resultaba caduca para la época, pues los diversos sectores sociales-obreros y campesinos primordialmente- no se sentían identificados con esta candidatura.

Alvarado contaba con numerosos seguidores que se encontraban principalmente en el sureste del país. Sin embargo, pese a coincidir en muchos aspectos con las políticas sonorenses, nunca pudo convertirse en un personaje aglutinador y, en cambio, encontró muchos opositores.

Por su parte, Obregón y los sonorenses entendieron la dinámica del país y lo que este requería: la clave estaba en conseguir el equilibrio entre los diversos grupos dispersos y molestos con el gobierno carrancista. Buscaron la armonía entre el capital y los trabajadores, del campo y de la fábrica, y extendieron una política de conciliación que abarcó a los enemigos de Carranza, algunos en el exilio. Obregón, hombre pragmático, supo que una política incluyente lo llevaría a la presidencia.

Esta postura contrastó notablemente con lo realizado por los otros tres candidatos, Alvarado, González y Bonillas. Una vez triunfante el Plan de Agua Prieta podía iniciarse la etapa de reconstrucción nacional, la resolución de los problemas sociopolíticos. El impulso de una nueva política de reunificación arrancó en 1920 con la muerte de Carranza. Fue así como una nueva coalición gobernante tomó el dominio del país.

\section{LISTA DE REFERENCIAS}

Aguilar Camín, H. (1986). La frontera nómada: Sonora y la revolución mexicana. México: Siglo XXI.

Alarcón Menchaca, L. (2008). José María Maytorena. Una biografía política. Zapopan: El Colegio de Jalisco/El Colegio de Sonora/Universidad Iberoamericana.

Alessio Robles, M. (2010). Memorias (t. II). México: InEHrM/Gobierno del Estado de Coahuila.

Alvarado, S. (1919). La reconstrucción de México (3 tt.). México: J. Ballesca y Cia.

Alvarado, S. (1920). La traición de Carranza. Nueva York: [s. e.].

Buchenau, J. (2013). La primera campaña electoral del general Álvaro Obregón. México: FAPECFT (Boletín, 72).

\section{()(1) $(9$}


Capetillo, A. (1926). La rebelión sin cabeza: génesis y desarrollo del movimiento delahuertista. México: Botas.

Castro, P. (1998). Adolfo de la Huerta. La integridad como arma de la revolución. México: Siglo XXI/UAM-Iztapalapa.

Cumberland, C. (1975). La revolución mexicana. Los años constitucionalistas. México: FCE.

Fabela, I. (1973). Documentos históricos de la revolución mexicana (vol. XVIII). México: FCE/Jus.

Dulles, J. W. F. (1977). Ayer en México: una crónica de la revolución, 1919-1936. México: FCE.

Gantús, F. y Salmerón, A. (coords.) (2014). Prensa y elecciones. Formas de hacer política en el México decimonónico. México: Instituto Mora.

Gantús, F. (coord.) (2015). Elecciones en el México del siglo XIx. Las fuentes. México: Instituto Mora.

Gantús, F. (coord.) (2015). Elecciones en el México del siglo XIX. Las prácticas. México: Instituto Mora.

Garciadiego, J. (1995). La prensa durante la revolución mexicana. En A. Cano (coord.), Las publicaciones periódicas y la historia de México (pp. 71-88). México: UnAM/IIB.

González Marín, S. (2006). Prensa y poder político. La elección presidencial de 1940 en la prensa mexicana. México: Siglo XXI/IIB-UnAM.

Guzmán Esparza, R. (transcripción y comentarios) (1957). Memorias de don Adolfo de la Huerta según su propio dictado. México: Ediciones Guzmán.

José, G. (1992). Legislación electoral mexicana 1812-1921. Cambios y continuidades. MéxiCO: IIS-UNAM.

José, G. (1998). La campaña presidencial de 1923-1924 en México. México: IneHrm.

José, G. (coord.) (2012). Candidatos, campañas y elecciones presidenciales en México. De la república restaurada al México de la alternancia, 1867-2006. México: IIS-UNAM.

José, G. (2014). La rebelión delahuertista: sus orígenes y consecuencias políticas, económicas y sociales. En J. Garciadiego (coord.), El ejército mexicano. 100 años de historia (pp. 213-270). México: Colmex.

Joseph, G. M. (1992). Revolución desde afuera. Yucatán, México y los Estados Unidos, 18801924. México: FCE.

León, L. L. (1987). Crónica del poder. En los recuerdos de un político en el México revolucionario. México: FCE.

Matute, Á. (1980). La carrera del caudillo. México: Colmex (Historia de la Revolución Mexicana, 8).

Matute, Á. (1985), Contraespionaje político y sucesión presidencial. Correspondencia de Trinidad W. Flores sobre la primera campaña electoral de Álvaro Obregón. México: IIH-UNAM.

\section{()(1) $(3$}


Matute, Á. (2002). Del Ejército Constitucionalista al Ejército nacional. En La revolución mexicana: actores, escenarios y acciones. Vida cultural y política, 1901-1929 (pp. 137-160). México: INEHRM/Océano.

Paoli Bolio, F. J. (1984). Yucatán y los orígenes del nuevo Estado mexicano. Gobierno de Salvador Alvarado, 1915-1918. México: Era.

Paoli Bolio, F. J. (1994). Salvador Alvarado, estadista y pensador (Antología). México: FCE. Pérez de Sarmiento, M. (2016). ¿Y antes de Alvarado? México: Área Maya.

Pizarroso Quintero, A. (1999). La historia de la propaganda: una aproximación metodológica. Historia y Comunicación Social, 4, 145-171.

Plasencia de la Parra, E. (1998). Personajes y escenarios de la rebelión delahuertista, 19231924. México: IIS-UnAm/Miguel Ángel Porrúa.

Ramírez Hurtado, L. (2010). Imágenes del olvido, 1914-1994. Discurso visual, manipulación y conmemoraciones de la Convención Revolucionaria de Aguascalientes. Aguascalientes: CCSH-UAA.

Serna, A. M. (2007). Periodismo, Estado y opinión pública en los inicios de los años veinte (1919-1924). Secuencia, 68, 57-85. DoI: http://dx.doi.org/10.18234/secuencia. v0i68.1005

Serna, A. M. (2014). Prensa y sociedad en las décadas revolucionarias (1910-1940). Secuencia, 88, 111-149. DoI: http://dx.doi.org/10.18234/secuencia.v0i88.1217

Taracena, A. (1992). La verdadera revolución mexicana: 1918-1921. México: Porrúa.

\section{OTRAS FUENTES}

\section{Hemerografía}

El Demócrata.

El Heraldo de México.

El Monitor Republicano.

El Universal. 